DOI : https://doi.org/10.24843/JFU.2020.v09.i01.p02

pISSN: 2301-7716; eISSN: 2622-4607

Jurnal Farmasi Udayana, Vol 9, No 1, Tahun 2020, 13-18

\title{
Analisis Efektivitas Biaya Penggunaan Bronkodilator dibandingkan Kombinasi Bronkodilator-Kortikosteroid pada Pasien Penyakit Paru Obstruktif Kronik (PPOK)
}

\author{
Putu Rika Veryanti ${ }^{1 *}$, Ainun Wulandari ${ }^{2}$ \\ ${ }^{1,2}$ Fakultas Farmasi, Institut Sains dan Teknologi Nasional, Jl. Moh. Kahffi II, Jagakarsa, Jakarta Selatan, \\ 12630 \\ *E-mail: rikaveryanti@,istn.ac.id
}

Riwayat artikel: Dikirim: 17/12/2019; Diterima: 01/02/2020, Diterbitkan: 25/06/2020

\begin{abstract}
Chronic Obstructive Pulmonary Disease (COPD) is a chronic airway disease characterized by slow and progressive airflow. Bronchodilators and corticosteroids are the first choice therapy in COPD patients. The appropriate therapy is expected to reduce morbidity and mortality in COPD patients. One of the causes of high mortality due to COPD is the result of ineffective therapy. Ineffective therapy of COPD could reduce clinical outcomes and increase patient costs. The purpose of this study was to compare the cost-effectiveness between groups of COPD patients who received bronchodilator therapy compared with groups of patients who received bronchodilator-corticosteroid combination therapy. This study was an observational study with a cohort study design. Data was collected at Fatmawati General Hospital in May-August 2019. The results showed that the average cost of COPD patients who only received bronchodilators was cheaper compared to the combination of bronchodilators and corticosteroids ( $\operatorname{Rp} 342,384,-$ vs $\operatorname{Rp} 615,201,-)$. But the effectiveness between the two groups of patients was the same (16.67\%). The value of ACER (Average Cost Effective Ratio) for bronchodilators was IDR 20,538, while ACER for bronchodilator-corticosteroid combinations is IDR 36,904. Based on the results of the study, we concluded that the use of bronchodilators is more cost-effective compared to bronchodilatorcorticosteroid combinations in COPD patients.
\end{abstract}

Keywords: Cost-Effectiveness Analysis, Bronchodilator, Bronchodilator-Corticosteroid, COPD

\section{ABSTRAK}

Penyakit Paru Obstruktif Kronik (PPOK) adalah penyakit kronis saluran napas yang ditandai dengan hambatan aliran udara dan bersifat progresif lambat yang semakin lama semakin memburuk. Bronkodilator dan kortikosteroid merupakan obat pilihan pertama yang digunakan pada pasien PPOK. Pemberian terapi yang tepat diharapkan dapat menurunkan angka morbiditas maupun mortalitas pada pasien PPOK. Salah satu hal yang menjadi penyebab tingginya angka kematian akibat PPOK adalah hasil terapi yang tidak efektif. Terapi obat yang tidak efektif dapat menurunkan outcome klinis dan meningkatkan biaya yang dikeluarkan pasien. Tujuan dari penelitian ini adalah unutk membandingkan efektivitas-biaya antara kelompok pasien PPOK yang mendapatkan terapi bronkodilator dibandingkan dengan kelmpok pasien yang mendapatkan terapi kombinasi bronkodilatorkortikosteroid. Penelitian ini merupakan penelitian observasional dengan desain studi cohort. Pengambilan data dilakukan di RSUP Fatmawati pada bulan Mei-Agustus 2019. Hasil penelitian menunjukkan bahwa rata-rata biaya pengobatan pasien yang hanya memperoleh bronkodilator saja lebih murah dibandingkan dengan kombinasi bronkodilator dan kortikosteroid (Rp 342.384,- vs Rp 615.201,-). Namun efektivitas diantara kedua kelompok pasien sama (16,67\%). Nilai ACER (Average Cost Effective Ratio) bronkodilator adalah Rp 20.538,- sedangkan ACER untuk kombinasi bronkodilator-kortikosteroid sebesar Rp 36.904,-. Berdasarkan hasil penelitian dapat disimpulkan bahwa penggunaan bronkodilator lebih cost-effective dibandingkan dengan kombinasi bronkodilator-kortikosteroid pada passien PPOK.

Kata Kunci: Analisis Efektivitas-Biaya, Bronkodilator, Bronkodilator-Kortikosteroid, PPOK 
DOI : https://doi.org/10.24843/JFU.2020.v09.i01.p02

pISSN: 2301-7716; eISSN: 2622-4607

Jurnal Farmasi Udayana, Vol 9, No 1, Tahun 2020, 13-18

\section{PENDAHULUAN}

Penyakit Paru Obstruktif Kronik (PPOK) merupakan penyakit kronis saluran napas yang ditandai dengan obstruksi jalan napas yang progresif. Di indonesia, prevalensi pasien PPOK cukup tinggi yaitu sebesar 3,7\%. Bronkodilator dan kortikosteroid merupakan obat pilihan pertama yang digunakan pada pasien PPOK. Bronkodilator dapat menyebabkan relaksasi otot polos jalur udara dan meningkatkan pengosongan paru selama pernapasan. Sedangkan golongan obat kortikosteroid berfungsi untuk menekan inflamasi yang terjadi. Tujuan pemberian terapi pada pasien PPOK adalah untuk mencegah gagal nafas yang dapat berdampak pada kematian. (Kementrian Kesehatan Republik Indonesia, 2013; Perhimpunan Dokter Paru Indonesia, 2011)

Namun sayangnya, angka kematian akibat PPOK terus meningkat. World Health Organization (WHO) memperkirakan kematian akibat PPOK di dunia akan menjadi peringkat ketiga setelah penyakit jantung koroner pada tahun 2030. (WHO, 2018) Salah satu hal yang menjadi penyebab tingginya angka kematian akibat PPOK adalah pengobatan yang tidak efektif. (Sugiharta et al., 2016) Terapi obat yang tidak efektif akan berpengaruh pada biaya yang dikeluarkan pasien, pihak rumah sakit maupun pemerintah.(Andayani TM., 2013; Direktorat Jenderal Bina Kefarmasian dan Alat Kesehatan, 2013) Beberapa penelitian menyebutkan bahwa terjadi perbedaan tarif riil rumah sakit dengan tarif yang dibayarkan BPJS (INA-CBG'S). Perbedaan tarif tersebut menyebabkan kerugian pada pihak rumah sakit.(Azalea et al., 2016; Yuniarti et al., 2015)

Berbagai hal telah dilakukan untuk mengidentifikasi penyebab ketidak-efektivan terapi dan untuk mencegah defisit anggaran rumah sakit. Diantaranya adalah dengan melakukan evaluasi pengobatan dan analisis biaya perawatan di rumah sakit. Pada penelitian yang pernah dilakukan Sugiharta dkk pada tahun 2016, diketahui bahwa penambahan kortikosteroid pada terapi bronkodilator untuk pasien PPOK menghasilkan outcome klinis yang tidak berbeda secara signifikan dibandingkan dengan pengobatan bronkodilator saja. Sedangkan penelitian mengenai analisis biaya perawatan di rumah sakit menunjukkan bahwa komponen tarif rumah sakit terbesar adalah biaya obat.(Dumaris, 2018)

Upaya yang dapat dilakukan untuk mengatasi permasalahan di atas adalah dengan penerapan prinsip farmakoekonomi. Prinsip farmakoekonomi adalah mengukur dan membandingkan antara biaya dan hasil dari suatu pengobatan. Untuk dapat meringankan pengeluaran biaya pasien, rumah sakit maupun pemerintah adalah dengan melakukan analisis efektivitas biaya (Cost Effectiveness Analysis). Cost Effectiveness Analysis adalah salah satu metode farmakoekonomi yang bertujuan untuk membandingkan biaya pengobatan dengan efektifitas terapi yang diberikan. Dalam analisis efektivitas biaya, seluruh biaya yang dikeluarkan (baik biaya langsung maupun biaya tak langsung) untuk menangani pasien akan dibandingkan dengan efektivitas nya.(Andayani TM., 2013; Direktorat Jenderal Bina Kefarmasian dan Alat Kesehatan, 2013)

Penelitian ini penting untuk dilakukan karena belum ditemukan adanya penelitian yang menganalisis efektivitas-biaya pada pengobatan pasien PPOK. Walaupun secara teori telah diketahui bahwa penggunaan bronkodilator dan kortikosteroid bermanfaat bagi pasien PPOK, namun di lapangan ditemukan bahwa penggunaan kombinasi kedua golongan obat tersebut tidak lebih efektif dibandingkan dengan terapi bronkodilator saja(Sugiharta et al., 2016). Padahal, penambahan kortikosteroid pada bronkodilator memberikan biaya yang lebih besar dibandingkan dengan pengobatan yang hanya menggunakan bronkodilator saja.

Penelitian ini dapat dijadikan bukti ilmiah untuk membantu pembuat kebijakan dalam menentukan pilihan atas alternatif pengobatan yang tersedia agar menjadi efisien dan ekonomis khususnya, pada pasien PPOK. Dengan demikian diharapkan dapat mengurangi angka kematian pada pasien PPOK dan mencegah potensi kerugian yang dialami pemerintah dan rumah sakit. 
DOI : https://doi.org/10.24843/JFU.2020.v09.i01.p02

pISSN: 2301-7716; eISSN: 2622-4607

Jurnal Farmasi Udayana, Vol 9, No 1, Tahun 2020, 13-18

\section{METODOLOGI PENELITIAN}

Penelitian dilakukan di RSUP Fatmawati dan pengambilan data dimulai pada bulan Mei sampai Agustus 2019. Analisis efektivitas biaya merupakan salah satu kajian farmakoekonomi yang dapat digunakan untuk membandingkan dua atau lebih intervensi kesehatan yang memberikan besaran efek berbeda. Perbandingan efektivitas biaya dilihat dari nilai Average Cost Effective Ratio (ACER) dan Incremental Cost Effective Ratio (ICER). ACER merupakan nilai yang menunjukkan perbandingan biaya yang dikeluarkan dengan efektivitas terapi. Nilai ACER yang lebih rendah menunjukkan bahwa kelompok tersebut lebih cost-effertive dibandingkan kelompok lainnya. Sedangkan Nilai ICER menunjukkan tambahan biaya yang diperlukan untuk mendapatkan efek dari penggantian obat A ke obat B. Dalam penelitian ini, yang dibandingkan adalah kelompok pasien PPOK dengan terapi bronkodilator saja dengan kelompok pasien PPOK yang diterapi dengan bronkodilator dan kortikosteroid. Kategori obat A (Bronkodilator+Kortikosteroid) adalah obat yang memiliki biaya yang lebih besar dibandingkan dengan Obat B (Bronkodilator saja). Nilai ACER dan ICER diperoleh dengan rumus sebagai berikut: (Andayani TM., 2013; Direktorat Jenderal Bina Kefarmasian dan Alat Kesehatan, 2013)

$$
\begin{aligned}
& \text { ACER }=\frac{\text { Biaya kesehatan }}{\text { Luaran Klinis }} \\
& \mathrm{ICER}=\frac{\text { Biaya A }- \text { Biaya B }}{\text { Efek A - Efek B }}
\end{aligned}
$$

Penelitian ini merupakan jenis penelitian cohort dan menggunakan teknik purposive sampling. Sampel ditentukan berdasarkan kriteria inklusi sebagai berikut:

1. Pasien terdiagnosa PPOK

2. Pasien yang mendapatkan terapi bronkodilator
3. Pasien yang mendapatkan terapi bronkodilator dan kortikosteroid

4. Pasien yang memiliki catatan pemeriksaan gas darah $\left(\mathrm{PaO}_{2}\right.$ dan $\left.\mathrm{PaCO}_{2}\right)$ yang lengkap

5. Pasien yang memiliki data biaya pengobatan selama di rawat di rumah sakit

Sedangkan kriteria eksklusi dalam penelitian ini adalah pasien dengan pulang paksa.

Selanjutnya sampel yang diperoleh dibagi menjadi 2 kelompok. Kelompok I merupakan kelompok pasien yang menerima pengobatan bronkodilator saja, sedangkan kelompok II merupakan kelompok pasien yang menerima pengobatan bronkodilator dan kortikosteroid.

Data yang diperoleh berupa karakteristik pasien, nilai gas darah $\left(\mathrm{PaO}_{2}\right.$ dan $\left.\mathrm{PaCO}_{2}\right)$ serta biaya obat bronkodilator dan kortikosteroid selama menjalai perawatan di rumah sakit. Data tersebut selanjutnya diolah untuk mendapatkan gambaran mengenai:

1. Rata-rata biaya (dalam rupiah) obat bronkodilator dan kortikosteroid yang dikeluarkan untuk menangani pasien PPOK pada masing-masing kelompok pasien. Seluruh biaya pengobatan bronkodilator dan kortikosteroid dijumlahkan kemudian dibagi jumlah total sampel pada masing-masing kelompok.

2. Perbandingan efektivitas terapi bronkodilator dan kombinasi bronkodilator-kortikosteroid pada pasien PPOK.

3. Luaran klinis (efektivitas terapi) ditentukan dari perubahan nilai $\mathrm{PaO}_{2}$ dan $\mathrm{PaCO}_{2}$ pasien. Jumlah pasien yang selama perawatan mengalami perbaikan nilai gas darah $\left(\mathrm{PaO}_{2}=75-100 \mathrm{mmHg} ; \mathrm{PaCO}_{2}=\right.$ 35-45 $\mathrm{mmHg}$ ) dihitung dalam bentuk persentase pada masing-masing kelompok.

4. Nilai ACER pada masing-masing kelompok dan ICER antara kedua kelompok pasien. Nilai yang dihasilkan tersebut selanjutnya diintepretasikan. 
DOI : https://doi.org/10.24843/JFU.2020.v09.i01.p02

pISSN: 2301-7716; eISSN: 2622-4607

Jurnal Farmasi Udayana, Vol 9, No 1, Tahun 2020, 13-18

\section{HASIL}

Hasil penelitian menunjukkan bahwa lakilaki lebih banyak menderita PPOK dibandingkan perempuan, yaitu sebesar 83,33\%. Menurut Riskesdas, kecenderungan laki-laki mengalami PPOK karena faktor kebiasaan merokok yang lebih dominan pada laki-laki (usia $\geq 15$ tahun: 64,9\%) dibandingkan perempuan (2,1\%). Penderita PPOK meningkat seiring bertambahnya usia. Hasil penelitian menunjukkan bahwa 90\% penderita PPOK adalah pasien dengan usia 45 tahun ke atas. Pada pasien usia lanjut, terjadi penurunan kekuatan otot paru dan daya tahan sistem kardiorespirasi. Hal ini disebabkan oleh menurunnya elastisitas parenkim paru sehingga menyebabkan penurunan fungsi paru. Berdasarkan data hasil penelitian yang ditampilkan pada tabel 1, diketahui bahwa prevalensi penderita PPOK lebih banyak terjadi pada laki-laki dan berusia lanjut.(Kementrian Kesehatan Republik Indonesia, 2013; Perhimpunan Dokter Paru Indonesia, 2011) Data karakteristik pasien ditampilkan pada tabel 1.
Distribusi pengunaan obat pada pasien PPOK dapat dilihat pada tabel 2. Tabel 2 menunjukkan sebagian besar terapi pengobatan pada pasien PPOK di RSUP Fatmawati menggunakan kombinasi antara golongan bronkodilator dan kortikosteroid (80\%). Penggunaan bronkodilator dapat memperbaiki gejala PPOK dengan menurunkan hiperinflasi paru dan efisiensi otot inspiratori (Riley \& Sciurba, 2019). Obat golongan bronkodilator juga dapat mempercepat waktu penyembuhan pada saat eksaserbasi akut, meningkatkan fungsi paru $\left(\mathrm{FEV}_{1}\right)$ dan memperbaiki hipoksemia di arteri $\left(\mathrm{PaO}_{2}\right)$, mengurangi risiko kekambuhan, kegagalan terapi, dan memperpendek masa rawatan di rumah sakit (Wisman et al., n.d.). Pada pasien PPOK dengan eksaserbasi akut terjadi peningkatan respon inflamasi sistemik, sehingga penggunaan kortikosteroid menjadi efektif pada kasus ini. Penggunaan bronkodilator bersama dengan kortikosteroid mampu mengurangi kejadian eksaserbasi pada pasien PPOK (Pleasants et al., 2018).

Tabel 1. Karakteristik Pasien PPOK

\begin{tabular}{|c|c|c|}
\hline Variabel & Jumlah (n) & Persentase $(\%)$ \\
\hline \multicolumn{3}{|l|}{ Jenis Kelamin } \\
\hline Laki-Laki & 50 & 83,33 \\
\hline Perempuan & 10 & 16,67 \\
\hline Total & 60 & 100 \\
\hline \multicolumn{3}{|l|}{ Usia } \\
\hline 36-45 tahun & 6 & 10 \\
\hline 46-55 tahun & 2 & 3,33 \\
\hline 56-65 tahun & 24 & 40 \\
\hline$>65$ tahun & 28 & 46,67 \\
\hline Total & 60 & 100 \\
\hline
\end{tabular}

Tabel 2. Terapi Pengobatan pada Pasien PPOK

\begin{tabular}{lcc}
\hline \multicolumn{1}{c}{ Terapi PPOK } & Jumlah Pasien $(\mathrm{n})$ & Persentase $(\%)$ \\
\hline Bronkodilaor & 12 & 20 \\
Bronkodilator+Kortikosteroid & 48 & 80 \\
Total & 60 & 100 \\
\hline
\end{tabular}


DOI : https://doi.org/10.24843/JFU.2020.v09.i01.p02

pISSN: 2301-7716; eISSN: 2622-4607

Jurnal Farmasi Udayana, Vol 9, No 1, Tahun 2020, 13-18

Tabel 3. Efektivitas terapi PPOK

\begin{tabular}{lccc}
\hline \multicolumn{1}{c}{ Terapi PPOK } & $\begin{array}{c}\text { Jumlah } \\
\text { Pasien (n) }\end{array}$ & $\begin{array}{c}\text { Jumlah Pasien dengan nilai } \\
\mathrm{PaO}_{2} \text { dan } \mathrm{PaCO}_{2} \\
\text { membaik }\end{array}$ & Efektivitas (\%) \\
\hline Bronkodilaor & 12 & 2 & 16,67 \\
Bronkodilator+Kortikosteroid & 48 & 8 & 16,67 \\
\hline
\end{tabular}

Tabel 4. Perbandingan Nilai ACER Terapi PPOK

\begin{tabular}{lcc}
\hline \multicolumn{1}{c}{ Variabel } & Bronkodilator & $\begin{array}{c}\text { Bronkodilator }+ \\
\text { kortikosteroid }\end{array}$ \\
\hline Rata-rata biaya obat per pasien (C) & Rp 342.384,- & Rp 615.201,- \\
Efektivitas terapi (E) & $16,67 \%$ & $16,67 \%$ \\
ACER (C/E) & Rp 20.538,- & Rp 36.904,- \\
\hline
\end{tabular}

Efektivitas pengobatan kedua kelompok pasien diukur berdasarkan perbaikan nilai gas darah pasien yaitu nilai $\mathrm{PaO}_{2}$ dan $\mathrm{PaCO}_{2}$. Nilai $\mathrm{PaO}_{2}$ dan $\mathrm{PaCO}_{2}$ pasien yang awalnya di atas atau di bawah normal sebelum terapi, kemudian mengalami perubahan (mendekati normal) setelah terapi dinyatakan mengalami perbaikan (pengobatan efektif). Perbandingan efektivitas kedua kelompok terapi ditampilkan pada tabel 3.

Tabel 3 menunjukkan bahwa jumlah pasien yang mengalami perbaikan nilai $\mathrm{PaO}_{2}$ dan $\mathrm{PaCO}_{2}$ pada kelompok bronkodilator adalah sebanyak 2 pasien dari total 12 pasien. Sedangkan pada kelompok pasien yang menerima terapi kombinasi bronkodilator dan kortikosteroid adalah sebanyak 8 pasien dari total 48 pasien. Pada penelitian ini diketahui bahwa pasien PPOK yang diterapi dengan obat golongan bronkodilator saja memiliki efektivitas yang sama dengan kelompok pasien yang diberi terapi kombinasi bronkodilator dan kortikosteroid, yaitu sebesar 16,67\%.

Berdasarkan tabel 4, dapat diketahui bahwa rata-rata biaya pengobatan pasien yang hanya memperoleh bronkodilator saja lebih murah dibandingkan dengan kombinasi bronkodilator dan kortikosteroid. Namun efektivitas diantara kedua kelompok pasien sama. Ketika biaya pengobatan dan efektivitas terapi dibandingkan, diperoleh nilai ACER (Average Cost Effective Ratio) bronkodilator Rp 20.538,- dan kombinasi bronkodilator-kortikosteroid sebesar Rp 36.904,-.

\section{PEMBAHASAN}

Nilai ACER yang diperoleh tersebut menunjukkan bahwa pada kelompok pasien yang menerima pengobatan bronodilator saja, untuk meningkatkan efektivitas sebesar 1\%, membutuhkan biaya sebesar Rp 20.538,-. Sedangkan pada pasien dengan kombinasi bronkodilator-kortikosteroid, pasien membutuhkan Rp 36.904,- untuk meningkatkan 1\% efektivitas terapi (Andayani TM., 2013; Direktorat Jenderal Bina Kefarmasian dan Alat Kesehatan, 2013). Dengan kata lain, berdasarkan hasil penelitian dapat disimpulkan bahwa penggunaan bronkodilator lebih cost-effective dibandingkan dengan penambahan kortikosteroid pada terapi bronkodilator.

\section{KESIMPULAN}

Berdasarkan hasil penelitian, dapat disimpulkan bahwa penggunaan bronkodilator lebih cost-effective dibandingkan dengan kombinasi bronkodilator-kortikosteroid pada pasien PPOK.

\section{UCAPAN TERIMA KASIH}

Kami mengucapkan terimakasih kepada Kementrian Riset dan Teknologi Republik Indonesia atas hibah tahun anggaran 2019 dengan No kontrak: 42/AKM/MONOPNT/2019. Kami 
DOI : https://doi.org/10.24843/JFU.2020.v09.i01.p02

pISSN: 2301-7716; eISSN: 2622-4607

Jurnal Farmasi Udayana, Vol 9, No 1, Tahun 2020, 13-18

juga mengucapkan terimakasih kepada Rumah Sakit Umum Pusat Fatmawati atas kerjasamanya dalam penelitian ini.

\section{DAFTAR PUSTAKA}

Andayani TM. (2013). Farmakoekonomi Prinsip dan Metodologi. Bursa Ilmu.

Azalea, M., Andayani, T. M., \& Satibi, S. (2016). Analisis Biaya Pengobatan Penyakit Ginjal Kronis Rawat Inap Dengan Hemodialisis Di Rumah Sakit. Jurnal Manajemen Dan Pelayanan Farmasi (Journal of Management and Pharmacy Practice), 6(2), 141-150.

https://doi.org/10.22146/JMPF.266

Direktorat Jenderal Bina Kefarmasian dan Alat Kesehatan. (2013). Pedoman Penerapan Kajian Farmakoekonomi. Kementrian Kesehatan Republik Indonesia.

Dumaris, H. (2018). Analisis Perbedaan Tarif Rumah Sakit dan Tarif INA-CBG's Pelayanan Rawat Jalan di RSUD Budhi Asih Jakarta Tahun 2015. Jumal Administrasi Rumah Sakit Indonesia, 3(1). https://doi.org/10.7454/ARSI.V3I1.2209

Kementrian Kesehatan Republik Indonesia. (2013). Riset Kesehatan Dasar (RISKESDAS). Kemenkes RI.

Perhimpunan Dokter Paru Indonesia. (2011). Penyakit Paru Obstruktif Kronik. (PPOK) Edisi

Buku Lengkap: Pedoman Diagnosis Dan Penatalaksanaan di Indonesia. Perhimpunan Dokter Paru Indonesia.

Pleasants, R. A., Wang, T., Xu, X., Beiko, T., Bei, H., Zhai, S., \& Drummond, M. B. (2018). Nebulized corticosteroids in the treatment of COPD exacerbations: Systematic review, meta-analysis, and clinical perspective. Respiratory Care, 63(10), 1302-1310. https://doi.org/10.4187/respcare.06384 Riley, C. M., \& Sciurba, F. C. (2019). Diagnosis and Outpatient Management of Chronic Obstructive Pulmonary Disease: A Review. In JAMA - Journal of the American Medical Association (Vol. 321, Issue 8, pp. 745-746). American Medical Association. https://doi.org/10.1001/jama.2019.0131 Sugiharta, S., Rianti, A., STIKes Mitra Keluarga, D., Fakultas Farmasi Universitas Pancasila Jakarta, D., \& Farmasi RSUP Fatmawati Jakarta Selatan, I. (2016). Evaluation of Treatment Bronchodilators and Corticosteroids in COPD Patients in RSUP Fatmawati Inpatient Jakarta Period.

SOCLAL CLINICAL PHARMACY INDONESLA JOURNAL, 1(1).

WHO. (2018). Chronic Respiratory Diseases: Burden of COPD.

www.who.int/repiratory/copd/burden/en/ Wisman, B. A., Mardhiyah, R., Daniel Tenda, E., Pulmonologi, D., Perawatan, D., \& Kritis, P. (n.d.). Pendekatan Diagnostik dan Tatalaksana Penyakit Paru Obstruktif Kronik GOLD D: Sebuah Laporan Kasus.

Yuniarti, E., Amalia, A., \& Handayani, T. M. (2015). Analsis Biaya Terapi Penyakit Diabetes Melitus Pasien Jaminan Kesehatan Nasional di RS PKU Muhammadiyah Yogyakarta - Perbandingan Terhadap Tarif INA CBGs. Jurnal Kebijakan Kesehatan Indonesia : JKKI, 4(3), 97-103. https://doi.org/10.22146/JKKI.V4I3.36108 